\title{
Produto Verde: Uma Análise a partir do Ecodesign Pilot e da Teia das Estratégias do Ecodesign ${ }^{1}$
}

\author{
Green Product: An Analysis From Ecodesign Pilot and the Web of \\ Strategies Ecodesign
}

\section{Producto Verde: Un Análisis a partir del Ecodesign Pilot y de la Tela de Las Estrategias del Ecodesign}

\author{
Isabel Joselita Barbosa da Rocha Alves, Me. \\ Professora do Departamento de Contabilidade da Universidade \\ Estadual da Paraíba Rua Baraúnas, 351 - Bairro Universitário - \\ Campina Grande-PB, CEP 58429-500, Campina Grande, PB. \\ Fone/Fax: 83 3315.3300, e-mail: beljrocha@ibest.com.br
}

\author{
Lúcia Santana de Freitas, $\mathrm{Dr}^{\mathrm{a}}$ \\ Professora da Unidade Acadêmica de Administração e \\ Contabilidade da UFCG e do Programa de Pós-Graduação em \\ Recursos Naturais - PPGRN/UFCG Rua, Aprígio Veloso, 882, \\ Bairro Universitário, CEP: 58.429-900, Campina Grande, PB. \\ Fone: (83) 2101-1000, e-mail: lucia.sdefreitas@gmail.com
}

\section{RESUMO}

Este estudo objetivou analisar através do uso das ferramentas de ecodesign: Ecodesign PILOT e Teia das Estratégias do Ecodesign, se o banco Carambola, concebido como produto verde é de fato "verde". Os dados coletados junto ao idealizador do produto revelaram que os processos de extração e de produção de matérias-primas causam a maior parte dos impactos ambientais do produto. Contudo, destaca-se que nas demais fases do ciclo de vida os aspectos ambientais não são intensivos e que todas as estratégias apresentam baixa prioridade. Assim, pode-se concluir que o produto, com base nestas ferramentas, pode ser considerado verde.

Palavras-chave: Estratégia ambiental. Desempenho ambiental do produto. Ferramentas de Ecodesign.

\section{ABSTRACT}

This study aimed to analyze through the use of the tools of ecodesign: Ecodesign PILOT and Web Strategies of Ecodesign, if the bank Carambola, designed as a green product it is in fact "green." The data collected from the creator of the product revealed that the extraction and production of raw materials cause most of the environmental impacts of the product. However, it is emphasized that the remaining stages of the life cycle environmental aspects are not intensive and that all strategies have low priority. Thus, one can conclude that the basis of these tools can be considered green.

Keywords: Environmental strategy. Environmental performance of the product. Ecodesign tools.

\section{RESUMEN}

Este estudio tuvo como objetivo analizar a través del uso de las herramientas de ecodesign: Ecodesign PILOT y Tela de las Estrategias del Ecodesign, si el banco Carambola, concebido como producto verde es de hecho "verde". Los datos recolectados junto al idealizador del producto revelaron que los procesos de extracción y de producción de materias-primas causan la mayor parte de

\footnotetext{
${ }^{1}$ Artigo recebido em 19.10.2014. Revisado pelos pares em 02.03.2015 (blind review). Ajustado e Aceito para publicação em 17.03.2015. Recomendado para publicação por José Ribamar Marques de Carvalho (Editor Científico). Publicado em 01.04.2015. Organização responsável CCJS/UFCG.
}

REUNIR - Revista de Administração, Contabilidade e Sustentabilidade ISSN: 2237-3667 - Vol.5, nํ1, pp. 79-105, 2015. 
los impactos ambientales del producto. Pero, se destaca que en las demás fases del ciclo de vida los aspectos ambientales no son intensivos y que todas las estrategias presentan baja prioridad. Así, se puede concluir que el producto, con base en estas herramientas, puede ser considerado verde.

Palabras clave: Estrategia ambiental. Desempeño ambiental del producto. Herramientas de Ecodesign.

\section{INTRODUÇÃO}

Considerando o modelo vigente de desenvolvimento econômico e o entendimento de que este se torna ambientalmente insustentável ao longo do tempo, uma vez que, tal modelo baseia-se em excessivo consumo de recursos naturais, bem acima da capacidade de recuperação natural do planeta, somando-se aos diferentes impactos ambientais decorrentes das atividades produtivas, evidencia-se em todo o mundo uma crescente discussão e reconhecimento da necessidade de construção de um desenvolvimento econômico mais sustentável, envolvendo diferentes agentes responsáveis pelo processo de mudança, tais como, governo, organizações e cidadãos.

No que tange às organizações, especialmente as com fins lucrativos, têm começado a incorporar aspectos ambientais em seus modelos de gestão através da implementação de estratégias ambientais que vão desde as mais reativas, aquelas que respondem apenas a aspectos ambientais legais às mais proativas, aquelas que vão além das pressões legais e sociais. Neste sentido, muitas organizações têm criado e/ou melhorado seus produtos, tornando-os ambientalmente corretos ou verdes, sendo que tal comportamento tem sido fortemente anunciado através das atividades de marketing.

A adoção de estratégias ambientais, especialmente as mais proativas, desempenha um importante papel no contexto atual por proporcionar ganhos mútuos entre empresa e o meio ambiente, saindo de uma atuação baseada em um jogo de soma zero (ganha-perde) para outra baseada em soma positivo (ganha-ganha), uma vez que, por um lado, tais estratégias são capazes de gerar vantagens competitivas resultando em ganhos econômicos, melhoria da imagem da empresa, entre outros, e, por outro lado, reduzem os impactos ambientais decorrentes das atividades organizacionais, desde a redução de insumos até o descarte de produtos no fim de vida.

Diante deste contexto, tem sido relativamente crescente o uso de estratégias ambientais focadas na criação de produtos verdes. Entretanto, há diferentes formas de entendimento do que constitui um produto verde, tanto do ponto de vista prático/organizacional quanto do ponto de vista teórico.

$\mathrm{Na}$ literatura não há um concenso sobre o conceito e/ou características de produto verde. Um estudo realizado por Dangelico e Pontrandolfo (2010) destacam que os conceitos são muito amplos e contemplam diferentes dimensões, quais sejam: ecológica, política, capacidade de resposta social empresarial, comércio justo, conserv 
ação, sem fins lucrativos, o novo consumismo, sustentabilidade e igualdade, gerando confusão sobre o significado de verde.

Nessas diferentes percepções algo pode ser percibo como convergente, que o produto verde é aquele que apresenta um desempenho ambiental superior quando comparado a outros produtos similares. Partindo desse concenso, cabe ressaltar alguns questionamentos que são relevantes, tais como: essa superioridade é significativa para poder denominar o produto como verde? Há diferentes níveis de superioridade, em decorrência teríamos produtos menos verdes e mais verdes? Que parâmetros as organizações poderiam utilizar para avaliar o quanto seus produtos são verdes? Como os consumidores poderiam identificar produtos verdes?

Assim sendo, faz-se necessário o uso de ferramentas de gestão ambiental que possam avaliar o desempenho ambiental do produto, principalmente considerando todas as etapas do seu ciclo de vida, a exemplo do ecodesign.

O ecodesign consiste no desenvolvimento de produtos que além da inclusão dos atributos: eficiência, qualidade, funcionalidade, estética, custo, ergonomia, entre outros, se inclui o atributo ambiental, ou seja, reduz os impactos ambientais causados pelo produto ao longo de seu ciclo de vida. Para van Hemel e Cramer (2002), pode-se atribuir ao ecodesign o significado de uma discussão sistemática e consistente para melhorar o perfil ambiental do produto em todas as fases do ciclo de vida, incluindo reciclagem adequada e disposição. Atualmente pode se dispor de diversas ferramentas de ecodesign, das mais simples as mais sofisticadas. Dentre as várias ferramentas destacam-se o Ecodesign PILOT e a Teia das Estratégias do Ecodesign (TEE).

O Ecodesign PILOT é uma ferramenta de software usada para a identificação e aplicação de estratégias de Ecodesign em desenvolvimento de produtos. Enquanto que a TEE, apresentada por Brezet e van Hemel (1997), se caracteriza como um conjunto de estratégias de ecodesign bastante difundido adotado universalmente. De fácil utilização, estas ferramentas funcionam como um guia para o designer melhorar o perfil ambiental do produto.

Face ao exposto, considerando a necessidade da inclusão da variável ambiental no desenho de produtos e que atualmente há um grande número de empresas que procura apresentar seus produtos como produtos verdes, o presente estudo define o seguinte problema de pesquisa: os produtos concebidos como verdes são realmente verdes? Na busca de resposta para a questão de pesquisa formulada o presente estudo teve como objetivo analisar através do uso combinado de duas ferramentas de ecodesign, o Ecodesign PILOT e a TEE se um produto concebido como verde é de fato "verde".

Além desta parte introdutória, o artigo apresenta em seu referencial teórico, algumas ponderações acerca das características de "produto verde" e das ferramentas 
de ecodesign: Ecodesign PILOT e TEE. Em seguida, são apresentadas a metodologia, a apresentação e análise dos resultados e por fim as considerações finais.

\section{REFERENCIAL TEÓRICO}

A literatura que aborda a incorporação de requisitos ambientais quando da concepção de produtos, ou seja, o ecodesign, tais produtos recebem diferentes denominações, tais como, produto verde, eco-produto, produto limpo, produto sustentável, entre outras, bem como, diferentes tipos de requesitos ambientais. Neste sentido, para Dangelico e Pontrandolfo (2010), os conceitos apresentados são muito amplos e abordam diferentes dimensões gerando confusão sobre o significado de verde e não fornece instruções claras para as empresas dispostas a se tornarem "verdes", conforme demonstrado na Fig. 1.

\begin{tabular}{|c|c|}
\hline Autores & Características associadas ao produto verde \\
\hline $\begin{array}{l}\text { Shrivastava } \\
\text { e Hart (1995) }\end{array}$ & $\begin{array}{l}\text { - baixo impacto ambiental durante o uso; } \\
\text { - fácil compostagem, reutilizados ou reciclados ao término da vida útil. }\end{array}$ \\
\hline $\begin{array}{l}\text { Roy et al } \\
(1996)\end{array}$ & $\begin{array}{l}\text { - eficiente em energia; } \\
\text { - facilmente reparável; } \\
\text { - projetado para durar ou para ser reutilizado, recondicionado ou reciclado; } \\
\text { - gerar poluição e desperdício mínimos; } \\
\text { - pode ser disposto com segurança; } \\
\text { - uso mínimo de materiais, incluindo a embalagem; } \\
\text { - fabricados a partir de recursos renováveis ou abundantes, ou materiais reciclados; } \\
\text { - não prejudicial à saúde humana. }\end{array}$ \\
\hline $\begin{array}{l}\text { Luttropp e } \\
\text { Lagerstedt } \\
\quad(2006)\end{array}$ & $\begin{array}{l}\text { - não usar substâncias tóxicas; } \\
\text { - minimizar o consumo de energia e recurso nas fases de produção e transporte; } \\
\text { - usar características estruturais e materiais de alta qualidade para minimizar o peso; } \\
\text { - minimizar o consumo de energia e recursos na fase de uso; } \\
\text { - promover a reparação, melhorias e reciclagem; } \\
\text { - promover vida longa. }\end{array}$ \\
\hline $\begin{array}{l}\text { Ljungberg } \\
\text { (2007) }\end{array}$ & $\begin{array}{l}\text { - reduzir os materiais e o uso de energia para um produto; } \\
\text { - reduzir as emissões, dispersão e criação de produtos tóxicos; } \\
\text { - aumentar a quantidade de materiais recicláveis; } \\
\text { - maximizar o uso sustentável dos recursos renováveis; } \\
\text { - estender a vida útil de um produto; } \\
\text { - avaliar e minimizar o impacto ambiental; } \\
\text { - aumentar a eficiência na fase de uso. }\end{array}$ \\
\hline
\end{tabular}

Figura 1. Revisão das características de produtos verdes

Fonte: Adaptado de Dangelico e Pontrandolfo, (2010). 
Dentre as características comuns associadas ao desenvolvimento de produtos verdes destacam-se: não causar danos ao meio ambiente, evitar o uso de materiais tóxicos, reduzir o uso de energia e de materiais, incluindo embalagens, usar materiais reciclados e aumentar a vida útil e capacidade de remanufaturamento do produto.

Fargnoli e Kimura (2006) consideram que o desenvolvimento de produtos verdes, independentemente do grau de inovação e das tarefas que o desig ner

tem de executar, pode ser considerada como uma atividade de design que envolve: demandas dos clientes, necessidades da empresa e da sociedade e requisitos legais. Assim, faz-se necessário que o designer faça uso de ferramentas que o auxilie, a exemplos do Ecodesign PILOT e da TEE.

De acordo com Hepperle et al (2010), cada fase do ciclo de vida de um produto gera um efeito para o meio ambiente que pode ser baixo ou significante, de uma duração a curto ou longo prazo. Para Venzke (2002), o uso do ecodesign implica em inovações de processos, produtos e serviços que reduzam os danos ambientais em todas as etapas do ciclo de vida.

Ottman et al. (2006, p. 24), afirmam que "embora nenhum produto consumido tenha um impacto zero sobre o meio ambiente, os termos "Produtos verdes" ou "Produtos ambientais" são comumente usados para descrever aqueles que se esforçam para proteger ou melhorar o ambiente natural pela conservação de energia e/ou recursos e reduzir ou eliminar o uso de agentes tóxicos, poluição e resíduos". Essa definição destaca os principais tipos de foco ambiental de desenvolvimento de produtos verdes, ou seja, energia, recursos, a poluição e o desperdício (DANGELICO \& PONTRANDOLFO, 2010).

Neste sentido, as ferramentas de ecodesign se caracterizam como instrumentos de apoio a projetos de produtos verdes. Em estudo realizado por Baumann; Boons e Bragd (2002) foram identificadas mais de 150 ferramentas de ecodesign, variando das mais simples, como os cheklists a mais complexas como sofisticados programas de computador. Essas podem ter abordagens qualitativas, quantitativas ou ambas. Existem ferramentas que possibilitam a avaliação dos impactos ambientais dos produtos em todas as fases do ciclo de vida, o que facilita a identificação de oportunidades de melhoria do desempenho ambiental do produto, a exemplo das ferramentas abordadas neste trabalho. 


\subsection{Estudos e Evidências Empíricas sobre Ecodesign}

Estudo da literatura sobre desenvolvimento de produtos verdes baseado em banco de dados contendo 650 artigos realizado por Baumann; Boons e Bragd (2002), classificaram os estudos de acordo com as perspectivas das seguintes áreas:

- Empresarial: a maior parte da literatura concentra-se em questões de integração do processo de desenvolvimento de produtos no nível estratégico das organizações, porém, poucas referências tratam da integração das questões de gestão às questões ambientais e atividades de desenvolvimento de produto. A maioria das referências reflete uma perspectiva ocidental com pouca ênfase em países em desenvolvimento e seus problemas ambientais específicos. Menos de $10 \%$ do material analisado foi testado ou baseado em experiências empíricas.

- Engenharia: pesquisa com esta perspectiva diz respeito ao desenvolvimento de estratégias de design ambiental, metodologias e técnicas para o desenvolvimento de produto, ou apenas "ferramentas". A maioria das publicações descreve conceitualmente as ferramentas, poucas se referem aos aspectos de uso ou de efetividade. As publicações, com conteúdo empírico, apresentam relatórios sobre os testes de novas ferramentas desenvolvidas nas universidades e testadas pelos pesquisadores em um estudo de caso da empresa. Diferentes tipos de ferramentas foram encontradas na literatura, desde simples checklists a sofisticados sistemas baseados em computadores, incluindo estratégias técnicas como a substituição de materiais ou desmaterialização.

- Política: trata das relações interorganizacionais que influenciam o desenvolvimento de produtos verdes. Muitas das referências são de natureza conceitual e não adota uma perspectiva sistêmica. A base empírica na qual os investigadores se baseiam é relativamente pequena, e o material empírico é frequentemente usado de um modo ilustrativo.

Refletindo sobre a literatura atual, percebe-se que nos últimos anos vários autores apresentaram uma abordagem focada no ciclo de vida do produto. É uma visão holística do produto a partir das matérias-primas até a fase de disposição (o assim chamado "do berço ao túmulo"), para sublinhar os problemas, impactos, as oportunidades e prioridades de intervenções entre os diferentes estágios do ciclo de vida do produto (HEPPERLE et al, 2010).

O desenvolvimento de produtos e design usando uma perspectiva de ciclo de vida tem despertado o interesse tanto das empresas quanto das autoridades. Do ponto de vista da empresa, o interesse vem da esperança de alcançar vantagens competitivas, e 
das autoridades, pela possibilidade potencial de diminuir os impactos ambientais e sobre a saúde a partir de produtos e contribuição para o consumo sustentável (JÖNBRINK \& MELIN, 2008).

Embora as pesquisas em ecodesign ainda sejam embrionárias, possivelmente por ser uma área de conhecimento nova (BAUMANN; BOONS \& BRAGD, 2002), nos últimos anos diversos trabalhos empíricos vêm contribuído para implantação desta ferramenta. O Quadro 2 apresenta alguns trabalhos.

\begin{tabular}{|c|c|c|c|c|}
\hline Autor & Foco & Local & Setor & Aplicação \\
\hline $\begin{array}{c}\text { Diehl; Crul e Bijma } \\
(2001) \\
\end{array}$ & Todo ciclo de vida & Costa Rica & Eletroeletrônico & Produto \\
\hline Venzke (2002) & $\begin{array}{c}\text { Identificação das } \\
\text { práticas associadas ao } \\
\text { ecodesign }\end{array}$ & Brasil & Moveleiro & Empresa \\
\hline $\begin{array}{l}\text { Hochschorner e } \\
\text { Finnveden (2003) }\end{array}$ & Todo ciclo de vida & Suécia & Automobilísitico & Produto \\
\hline Hur et al (2005) & Todo ciclo de vida & Coréia do Sul & Eletroeletrônico & Produto \\
\hline $\begin{array}{c}\text { Fargnoli e Kimura } \\
(2006)\end{array}$ & Todo ciclo de vida & Japão & Eletroeletrônico & Produto \\
\hline $\begin{array}{c}\text { Xing; Abhary e } \\
\text { Luong (2006) }\end{array}$ & $\begin{array}{c}\text { Redesenho para } \\
\text { reciclagem }\end{array}$ & Austrália & Eletroeletrônico & Produto \\
\hline $\begin{array}{c}\text { Masanet e Horvarh } \\
(2007)\end{array}$ & Reciclagem & Estados Unidos & Eletroeletrônico & Produto \\
\hline $\begin{array}{c}\text { Maria; Rainer e } \\
\text { Wolfgang (2007) }\end{array}$ & Todo ciclo de vida & Áustria & Eletroeletrônico & Produto \\
\hline $\begin{array}{c}\text { Jönbrink e Melin } \\
\text { (2008) }\end{array}$ & $\begin{array}{c}\text { Identificação dos } \\
\text { incentivos e barreiras } \\
\text { para implementação } \\
\text { do ecodesign }\end{array}$ & $\begin{array}{c}\text { Suécia, Noruega } \\
\text { e Finlândia }\end{array}$ & Diversos & Empresa \\
\hline $\begin{array}{c}\text { Schiavone; Pierini; e } \\
\text { Eckert (2008) }\end{array}$ & Todo ciclo de vida & Suiça & Automotivo & Empresa \\
\hline $\begin{array}{l}\text { Albino; Balice e } \\
\text { Dangelico (2009) }\end{array}$ & Todo ciclo de vida & $\begin{array}{c}\text { Diversos } \\
\text { (Europa, } \\
\text { América, Ásia) }\end{array}$ & $\begin{array}{c}\text { Diversos (8 setores, } \\
\text { entre eles: } \\
\text { Industrial, Energia e } \\
\text { Tecnologia) }\end{array}$ & $\begin{array}{c}\text { Empresas incluídas } \\
\text { na Dow Jones } \\
\text { Sustainability } \\
\text { World Index } \\
\text { (DJSWI) }\end{array}$ \\
\hline Muñoz et al (2009) & Todo ciclo de vida & China & $\begin{array}{c}\text { Componentes } \\
\text { eletroeletrônicos }\end{array}$ & Produto \\
\hline $\begin{array}{c}\text { Tomé e } \\
\text { Blumenschein } \\
(2010)\end{array}$ & $\begin{array}{c}\text { Aplicação de projeto } \\
\text { piloto compra } \\
\text { responsável }\end{array}$ & Brasil & Construção Civil & Empresa (23) \\
\hline $\begin{array}{c}\text { Wong; Lee e Yung } \\
(2010)\end{array}$ & $\begin{array}{l}\text { Fase de uso da } \\
\text { matéria-prima }\end{array}$ & China & Eletroeletrônico & Produto \\
\hline
\end{tabular}

Quadro 2 - Evidências empíricas sobre Ecodesign

Fonte: Dados da pesquisa, 2012.

REUNIR - Revista de Administração, Contabilidade e Sustentabilidade ISSN: 2237-3667 - Vol.5, nº1, pp. 79-105, 2015. 
Em diversos países há estudos de aplicação do ecodesign abrangendo todas as operações da empresa, ou em um ou mais produtos, sobretudo no setor eletroeletrônico. Geralmente, quando aplicado ao produto, o ecodesign tem foco em todas as fases do seu ciclo de vida.

Conforme pesquisa realizada por Santos (2009), em 2008 havia 318 pósgraduandos em design, realizando suas teses e dissertações no Brasil. Deste total, apenas $16 \%$ desenvolviam temas diretamente ligados ao ecodesign, com maioria das pesquisas concentradas nos estados do Rio de Janeiro, São Paulo, Paraná e Santa Catarina.

Verifica-se através de pesquisa realizada por Medeiros et al (2010), (gráfico 1) com base nos anais do Congresso Brasileiro de Pesquisa e Desenvolvimento em Design de 1994 a 2008 (excetuando-se o ano de 2000, devido a não acessibilidade aos anais), que o número de trabalhos sobre design tem apresentado um aumento substancial no período estudado. Entretanto, a participação de trabalhos abordando o ecodesign, não ultrapassa o percentual encontrado por Santos (2009) em sua pesquisa.

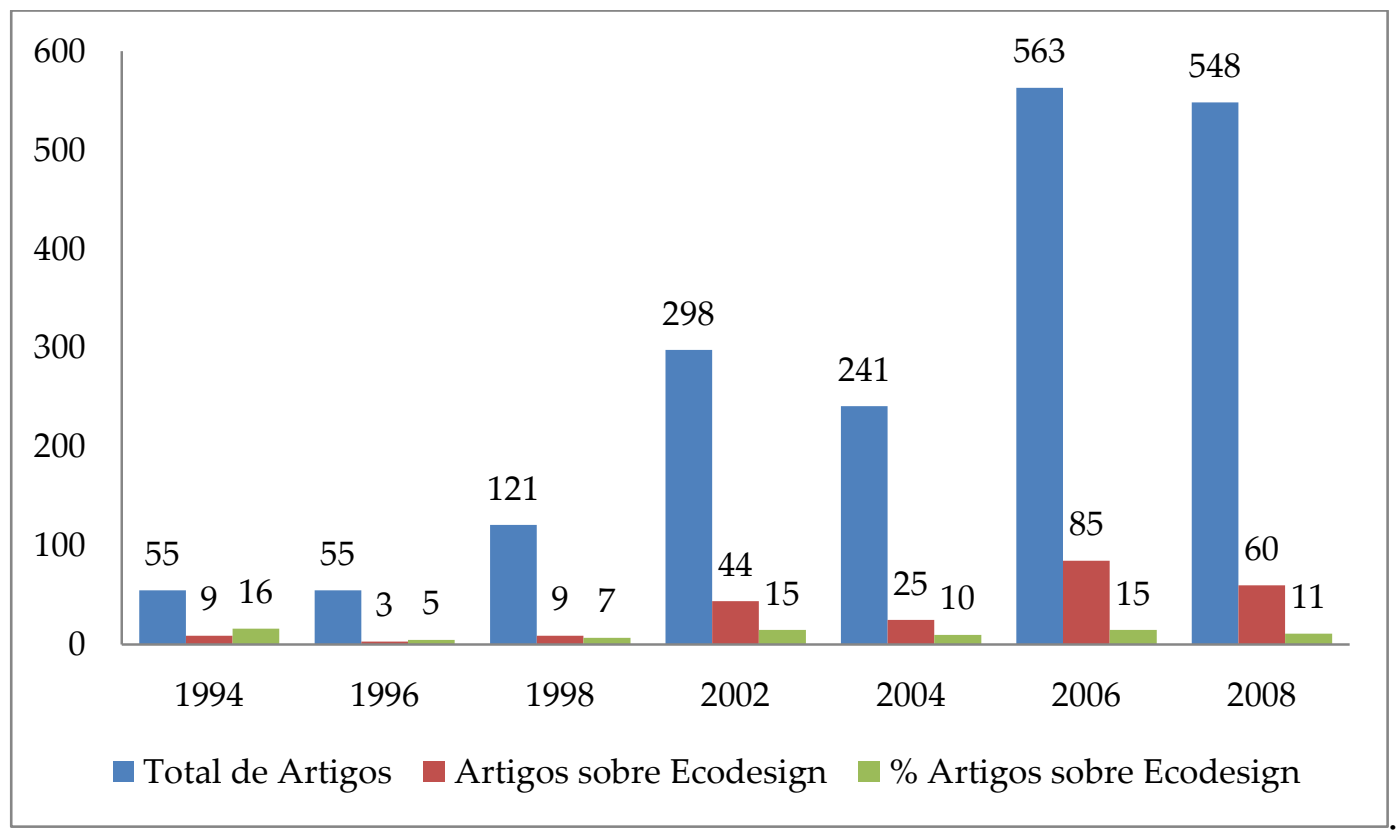

Gráfico 1 - Artigos dos Congressos Brasileiros de Pesquisa e Desenvolvimento em Design Fonte: Adaptado de Medeiros et al (2010)

Provavelmente uma das razões de haver poucas pesquisas abordando o ecodesign é o fato da pesquisa em design no Brasil ser uma atividade recente e ainda pouco estruturada e consolidada (SANTOS, 2009).

Contudo, tanto a indústria quanto as histórias de sucesso da academia usam o ecodesign

para provar que conceitualmente a concepção de compatibilidade ambiental em u REUNIR - Revista de Administração, Contabilidade e Sustentabilidade ISSN: 2237-3667 - Vol.5, nํ1, pp. 79-105, 2015. 
$\mathrm{m}$ produto oferece oportunidades únicas para melhorar o desempenho da empresa no mercado (BAUMANN; BOONS \& BRAGD, 2002).

Observa-se que a partir da difusão do conceito de sustentabilidade, as organizações passaram a incorporar à sua gestão tradicional, além dos aspectos econômicos, aspectos sociais e ambientais. Todavia, apesar de muitas empresas, principalmente as PME's, incluírem a variável ambiental por exigências legais, do mercado ou do consumidor, já se percebe a adoção de ferramentas de gestão ambiental, principalmente no segmento industrial.

O ecodesign é uma ferramenta de gestão ambiental, em que a empresa envida esforços para incorporar aspectos ambientais no desenvolvimento de seus produtos; aspectos ambientais que cobrem todo o ciclo de vida do produto, ou seja, do berço ao túmulo.

Neste sentido, o ecodesign, é primordial para fabricação de produtos verdes. O uso efetivo desta ferramenta contribui para o desenvolvimento de produtos que não causam danos ao meio ambiente, que evita o uso de materiais tóxicos ou perigosos, que reduz o uso de materiais e energia, que usa materiais reciclados, entre outros.

Atualmente para desenvolvimento de produtos que apresentem boa performance ambiental, os designers têm à sua disposição uma série de ferramentas de ecodesign, das mais simples às mais complexas. Dentre elas, destacam-se o Ecodesign PILOT e TEE por serem de fácil acesso e utilização e por cobrirem todo o ciclo de vida do produto.

Assim, considerando-se ainda que as ferramentas de ecodesign supracitadas se complementam, é possível utilizá-las para verificar como as estratégias de ecodesign de empresas voltadas para fabricação de produtos concebidos como verdes, podem contribuir para uma melhor performance ambiental dos produtos e empresas.

\subsection{Ecodesign Pilot}

O Ecodesign PILOT (Product Investigacion Learning and Optimizacion Tool) é uma ferramenta de software usada para a identificação e aplicação de estratégias de ecodesign em desenvolvimento de produtos desenvolvida pelo Instituto de Engenharia de Design da Universidade de Viena, cuja versão original foi desenvolvida em 2001, que permite identificar medidas concretas para melhoria do desempenho ambiental do produto.

A ferramenta inclui um programa utilitário chamado Assistente que contém seis formulários que contemplam todas as fases do ciclo de vida do produto. Com o auxílio destes formulários e por meio dos dados essenciais do produto, o Assistente identifica a fase do ciclo de vida com mais alto impacto ambiental, de forma que o produto possa ser classificado como dos tipos: Tipo A - Produto Intensivo em Matéria-prima; Tipo B - 
Produto Intensivo em Fabricação; Tipo C - Produto Intensivo em Transporte; Tipo D Produto Intensivo em Uso; Tipo E - Produto Intensivo em Disposição.

Após a classificação do produto, o Programa apresenta as recomendações das est ratégias de ecodesign mais adequadas para sua melhoria. De livre acesso no website www.ecodesign.at/pilot, o Ecodesign PILOT, versão 3, está disponível em 10 idiomas e o Assistente apenas em inglês e alemão, podendo ser utilizado tanto pelas organizações quanto por pesquisadores.

\subsection{Teia de Estratégias de Ecodesign (TEE)}

Desenvolvida pelo Programa das Nações Unidas para o Meio Ambiente (PNUMA), a TEE apresentada por Brezet e van Hemel (1997), se caracteriza como um conjunto de estratégias de ecodesign bastante difundido. A ferramenta é utilizada para avaliação preliminar do desempenho ambiental de um produto, o que permite a definição de prioridades de intervenção para que melhorias possam ser realizadas (FARGNOLI \& KIMURA, 2006).

Nascimento e Venzke (2006) reforçam que por meio de uma avaliação qualitativa, um produto pode ser avaliado e desenvolver estratégias para melhorar o seu desempenho ambiental.

Para subsidiar a avaliação do produto, a ferramenta apresenta oito estratégias genéricas de ecodesign que cobrem todo o ciclo de vida do produto e 33 princípios, classificadas em nível de componentes do produto, nível de estrutura do produto e nível de sistema do produto, conforme descrito na Fig. 3.

\begin{tabular}{|c|c|c|}
\hline & Estratégicas Genéricas & Princípios \\
\hline- & $\begin{array}{l}\text { @. Desenvolvimento de } \\
\text { novo conceito }\end{array}$ & $\begin{array}{l}\text { @.1 Desmaterialização } \\
\text { @.2 Uso compartilhado do produto } \\
\text { @.3 Integração de funções } \\
\text { @.4 Otimização funcional do produto ou } \\
\text { componente }\end{array}$ \\
\hline $\begin{array}{c}\text { Nível de } \\
\text { componentes } \\
\text { do produto }\end{array}$ & $\begin{array}{l}\text { 1. Seleção de materiais de } \\
\text { baixo impacto } \\
\text { 2. Redução do uso de } \\
\text { materiais }\end{array}$ & $\begin{array}{l}\text { 1.1 Materiais não agressivos } \\
\text { 1.2 Materiais renováveis } \\
\text { 1.3 Materiais reciclados } \\
\text { 1.4 Materiais de baixo conteúdo energético } \\
\text { 1.5 Materiais recicláveis } \\
\text { 2.1 Redução de peso } \\
\text { 2.2 Redução de volume } \\
\text { 2.3 Racionalização de transportes }\end{array}$ \\
\hline
\end{tabular}




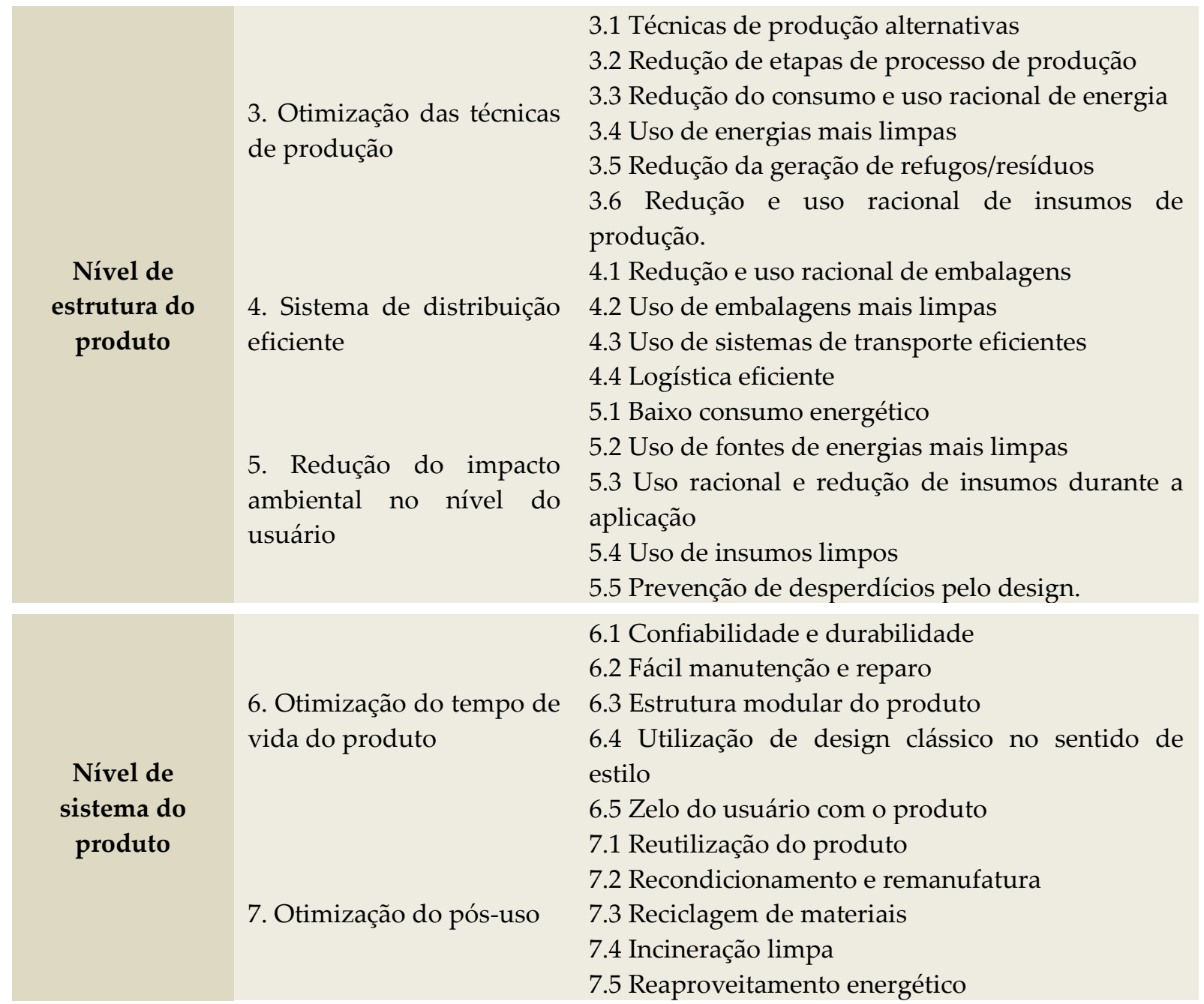

Figura 3. Estratégias de Ecodesign

Fonte: Adaptado de van Hemel e Cramer, (2002)

Os resultados da TEE são representados num gráfico tipo teia e representam uma variação de 20 pontos percentuais, que vai de $0 \%$ (centro da figura) até $100 \%$ (último círculo). A meta da ferramenta é prover as melhores opções para melhoria ambiental de um produto (FARGNOLI \& SAKAO, 2008).

\section{PROCEDIMENTOS METODOLÓGICOS}

Esta pesquisa, em relação aos objetivos propostos, classifica-se como exploratória e descritiva, uma vez que o estudo analisa as estratégias de ecodesign de um produto concebido como "verde", utilizando as ferramentas Ecodesign PILOT e TEE. Para Hair Jr. et al (2005), a pesquisa exploratória é realizada em área na qual há pouco conhecimento. A descritiva busca descrever as características de determinada população ou fenômeno, 
bem como estabelecer correlações entre variáveis e definir sua natureza, sem o compromisso de explicá-los (VERGARA, 2000).

Quanto ao método se optou pelo estudo de caso. Tal método diz respeito ao estudo de uma ou de poucas unidades, de maneira a permitir entendimento profundo e detalhado do que está sendo analisado (VERGARA, 2000; GIL, 2002).

O produto escolhido para análise foi o banco Carambola, móvel multi-uso que pode ser utilizado em áreas internas e externas, criado em 04/2010 e reconhecido internacionalmente como "produto verde". As informações foram obtidas junto ao idealizador do produto e gestor da empresa entre janeiro e março de 2012 através de entrevista semiestuturada e de dois questionários.

Para conhecer a intensividade dos aspectos ambientais do produto analisado (matéria-prima, fabricação, transporte, uso ou disposição) adotou-se, na íntegra, o questionário do Ecodesign PILOT. O segundo questionário foi elaborado a partir da TEE e do Ecodesign PILOT, no qual foram abordadas as oito estratégias de ecodesign, desmembradas em 34 dimensões, e, para as dimensões, elaboradas 71 afirmativas.

Para cada alternativa, tomando como base a ferramenta Ecodesign PILOT, as respostas do segundo questionário foram assinaladas considerando dois aspectos: percepção sobre a relevância e efetiva aplicação; uma vez que as afirmativas podem ter diferentes níveis de relevância e de aplicação, que a percepção de algo como relevante nem sempre resulta em sua aplicação e que a aplicação também é influenciada pelo nível de relevância percebido.

A percepção sobre a relevância apresentava três níveis: nenhuma relevância (0); pouca relevância (5) e muita relevância (10), e a efetiva aplicação quatro níveis: sempre aplico (1); quase sempre aplico (2); às vezes aplico (3) e não aplico (4). Com base nessas informações se pode verificar a percepção que se tem sobre a relevância dos aspectos de ecodesign e a efetiva aplicação de tais aspectos, para cada uma das oito estratégias de ecodesign.

Como as oito estratégias se apresentam de modos diferentes, fez-se necessário a identificação de quais estratégias devem ser prioritárias para que possam ser trabalhadas. A prioridade foi encontrada a partir do produto entre a relevância $(0,5,10)$ e a aplicação $(1,2,3,4)$, podendo chegar aos seguintes resultados: 0, 5, 10,15, 20, 30 e 40. Quanto mais alto for o resultado maior será a prioridade, ou seja, maior relevância e menor aplicação.

Considerando os possíveis resultados encontrados $(0,5,10,15,20,30$ e 40) para definir as prioridades de cada estratégia, e, como forma de dar mais consistência a análise, a prioridade foi classificada em três níveis: baixa (0-13), média (14-26) e alta (2740). Desta forma, cada estratégia teve suas respectivas dimensões analisadas e identificadas as prioridades de cada afirmativa. A prioridade de cada dimensão 
aplicável ao produto foi calculada por meio da média aritmética de suas respectivas afirmativas aplicáveis ao produto. A prioridade de cada estratégia foi calculada por meio da média aritmética de suas respectivas dimensões.

Quanto aos dados secundários, foram utilizados manuais, documentação e informações técnicas sobre o produto. Por fim, conforme as características e os objetivos do estudo, todos os dados obtidos foram tratados qualitativa e quantitativamente.

\section{APRESENTAÇÃO E DISCUSSÃO DOS RESULTADOS}

O banco Carambola foi criado em 04/2010 e lançado no mesmo ano no Salone Satellite em Milão, na Itália, e tem despertado o interesse das revistas especializadas em decoração de ambientes e design como a Vogue Moda, Casa Vogue, revista Kaza, entre outras.

O conceito do produto vem da forma da fruta carambola, sua estrutura é de aço carbono e a trama, feita artesanalmente, utiliza fios de algodão natural ou colorido o que dispensa a utilização de produtos químicos para seu tingimento ou uso de materiais auxiliares e de processo ambientalmente perigosos.

Todo processo produtivo é terceirizado. A estrutura é fabricada por uma empresa localizada no município de Esperança-PB e a trama por artesãos de Campina GrandePB.

Fabricado e comercializado para todo o Brasil, principalmente para as regiões Sul e Sudeste e Distrito Federal; a produção mensal é de, em média, 50 unidades. O produto tem uma dimensão de $0,50 \times 0,45 \mathrm{~m}$ e pesa $3,5 \mathrm{~kg}$, porém, quando solicitado pelo cliente, pode ser fabricado com outras dimensões ou adaptado para ser utilizado como mesa de apoio. A embalagem é confeccionada com papelão reciclado e pesa $0,3 \mathrm{~kg}$.

\subsection{Intensividade dos Aspectos Ambientais segundo o Ecodesign Pilot}

Para análise do banco Carambola utilizando o questionário do Ecodesign PILOT, foi considerado uso de 365 dias por ano e uma vida útil de 10 anos. Os materiais utilizados foram informados, conforme Fig. 4.

\begin{tabular}{|l|c|c|c|c|}
\hline \multicolumn{1}{c|}{$\begin{array}{c}\text { Partes do } \\
\text { produto/embalagens }\end{array}$} & Kg & Material & Classe & Descarte \\
Estrutura & 1,84 & Aço carbono & VI & Reuso \\
\hline Solda & 0,16 & Aço carbono & VI & Reuso \\
\hline Trama & 1,5 & Algodão orgânico & I & Aterro \\
\hline Caixa & 0,3 & Papelão reciclado & I & Reciclagem \\
\hline
\end{tabular}

Figura 4. Informações sobre o banco "Carambola" 
Fonte: Dados da pesquisa (2012)

No que se refere à manufatura do produto, considerou-se que não há geração de resíduos durante o processo produtivo, nem tampouco uso de materiais auxiliares e de processo ambientalmente perigosos. A produção é de 50 unidades/mês, e o consumo de energia para produção de cada unidade é de $0,11 \mathrm{kWh}$. No produto não há peças externas.

Quanto à distribuição, esta é feita através de transporte aéreo, em média 2000 km. O tipo de embalagem é descartável.

No que concerne ao uso do produto, dentre as alternativas do formulário, foi informado que é impossível o produto apresentar um risco potencial para o meio ambiente se for utilizado de forma inadequada ou em caso de mau funcionamento. No fim de vida, o produto pode ser reutilizado para o mesmo ou outro fim.

Com base nas informações acima, o Assistente do Ecodesign PILOT classificou o banco Carambola como tipo " $\mathrm{A}$ ", ou seja, a fase de "matéria-prima" é significante no que concerne aos aspectos ambientais do produto, assim foram recomendadas as seguintes estratégias:

Estratégias de alta prioridade:

a) selecionar os materiais adequados e

b) reduzir o consumo de material.

\section{Estratégias para serem realizadas mais tarde:}

a) otimizar o uso do produto;

b) otimizar a funcionalidade do produto;

c) aumentar a durabilidade do produto;

d) melhorar a manutenção e

e) melhorar a reparabilidade.

\section{Outras estratégias recomendadas:}

a) redução de transporte.

Quanto às estratégias de alta prioridade, as recomendações têm muita relevância e são sempre aplicadas, resultando em prioridade (10). Observou-se que a empresa utiliza matérias-primas renováveis (algodão orgânico); usa materiais recicláveis; os componentes do produto são separáveis; as matérias-primas (aço carbono e solda, sobretudo a solda que é um material tóxico), nas quantidades utilizadas, não apresentam problemas ao meio ambiente e usa apenas três tipos de materiais (aço carbono, solda e algodão orgânico), cujo consumo é reduzido por meio do design e mediante a integração de funções. A única exceção refere-se a "utilização de materiais reciclados", que não tem nenhuma relevância e não é aplicada, prioridade (0). Isto 
ocorre devido à impossibilidade de se utilizar o algodão orgânico reciclado na confecção da trama, bem como à inexistência de oferta no mercado local do aço carbono reciclado para confecção da estrutura do banco.

\subsubsection{Sugestões de Melhoria Ambiental para o Produto a partir do Ecodesign Pilot}

Apesar das medidas já adotadas pela empresa visando o desempenho ambiental do produto, recomenda-se como estratégia de alta prioridade substituir o aço carbono e a solda por madeira reciclada ou certifcada e parafusos, respectivamente, para montar a estrutura do banco.

Constata-se que, com a adoção da recomendação anterior, a empresa eliminará o uso de material tóxico (solda) e utilizará matéria-prima de fonte renovável (madeira), bem como reciclada e reciclável e utilizará materiais separáveis.

No que tange às estratégias para serem realizadas mais tarde, verificou-se que:

- Estratégias a e b: o produto é multifuncional, podendo ser utilizado como banco ou mesa de apoio;

- Estratégia c: a vida útil estimada do produto é longa (10 anos);

- Estratégias d: o produto não necessita de manutenção;

- Estratégia e: caso necessite, o produto pode ser reparado.

No que se refere à "redução de transporte" como outra estratégia recomendada, em face à quantidade produzida e mercado consumidor do banco Carambola, no momento, o transporte aéreo é o mais viável por apresentar custo mais baixo, rapidez e segurança.

\subsection{Estratégias de Ecodesign e suas Respectivas Prioridades a Partir da TEE}

$\mathrm{Na}$ Estratégia 0, que trata do desenvolvimento de novo conceito (Fig. 5), considerando-se os aspectos ambientais que devem ser incorporados na fase inicial do ciclo de vida do produto, a empresa percebe a "desmaterialização", o "uso compartilhado do produto" e a "integração de funções" como dimensões de muita relevância e sempre as aplicam, o que resultam em prioridade (10). A exceção se dá na "otimização funcional do produto" onde a "priorização de funções estéticas" e a "escolha de componentes que valorizem esteticamente o produto", apesar de sempre serem aplicadas têm pouca relevância, de forma que esta dimensão apresenta prioridade $(6,7)$. 


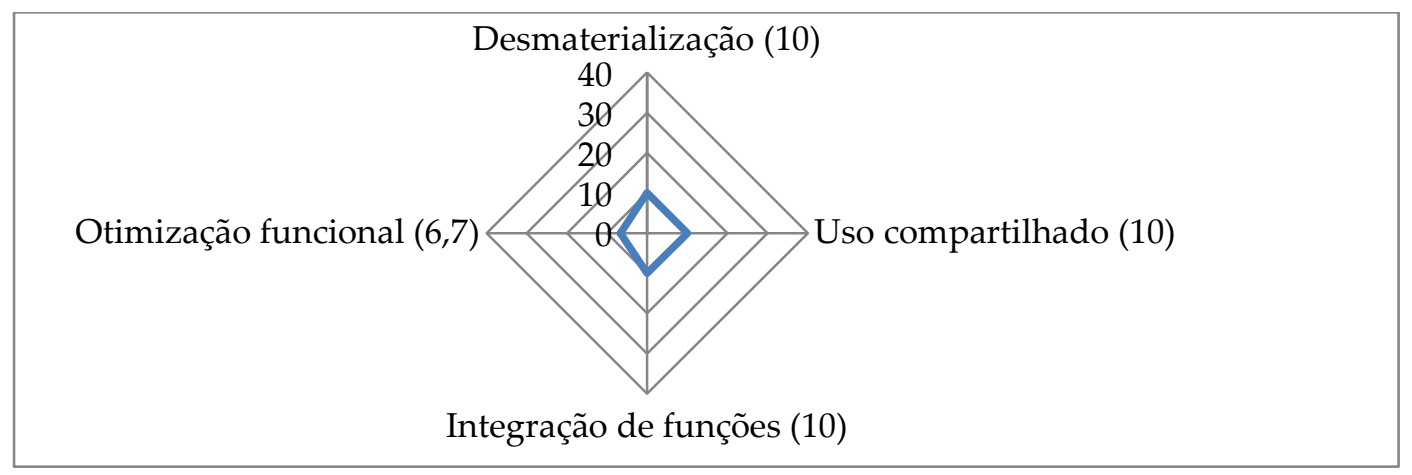

Figura 5. Estratégia 0: Desenvolvimento de um novo conceito Fonte: Dados da pesquisa, (2012).

A baixa prioridade da estratégia $0(\mathbf{9}, \mathbf{2})$, justifica-se pelo fato do produto conter apenas duas partes (estrutura de aço carbono e trama de algodão orgânico), as quais são de fácil acesso e fácil substituição; por poder ser utilizado por diferentes usuários em diferentes ocasiões, como banco ou mesa de apoio; por ter sido projetado ergonomicamente; integrar várias funções dentro do seu campo de utilização e despertar pensamentos positivos ao usuário, bem como ser devidamente adaptado às necessidades dos clientes, embora não tenha sido criado priorizando apenas funções estéticas.

Considerando que esta etapa do ciclo de vida do produto tem fortes implicações nas demais etapas, é extremamente importante pensar o produto considerando os aspectos ambientais.

No que tange à Estratégia 1 que aborda a seleção de materiais de baixo impacto (Fig. 6), a empresa percebe a "utilização de materiais não agressivos", de "materiais renováveis" e de "materiais recicláveis" como dimensões de muita relevância e sempre as aplicam, o que resultam em prioridade (10).

No que se refere à dimensão "materiais de baixo conteúdo energético", para a empresa o algodão orgânico demanda pouca energia em sua transformação, pois dispensa o uso de tintura, o que reduz também, o consumo de tinta e água. Entretanto, o mesmo não ocorre com o aço carbono e a solda, assim esta dimensão tem muita relevância e quase sempre é aplicada, culminando em prioridade (20).

Quanto à "utilização de materiais reciclados", dada à impossibilidade da utilização da trama de algodão orgânico reciclado e da pouca oferta pelo mercado do aço carbono reciclado, esta dimensão não apresenta nenhuma relevância e não é aplicada pela empresa, resultando em prioridade zero (0). 


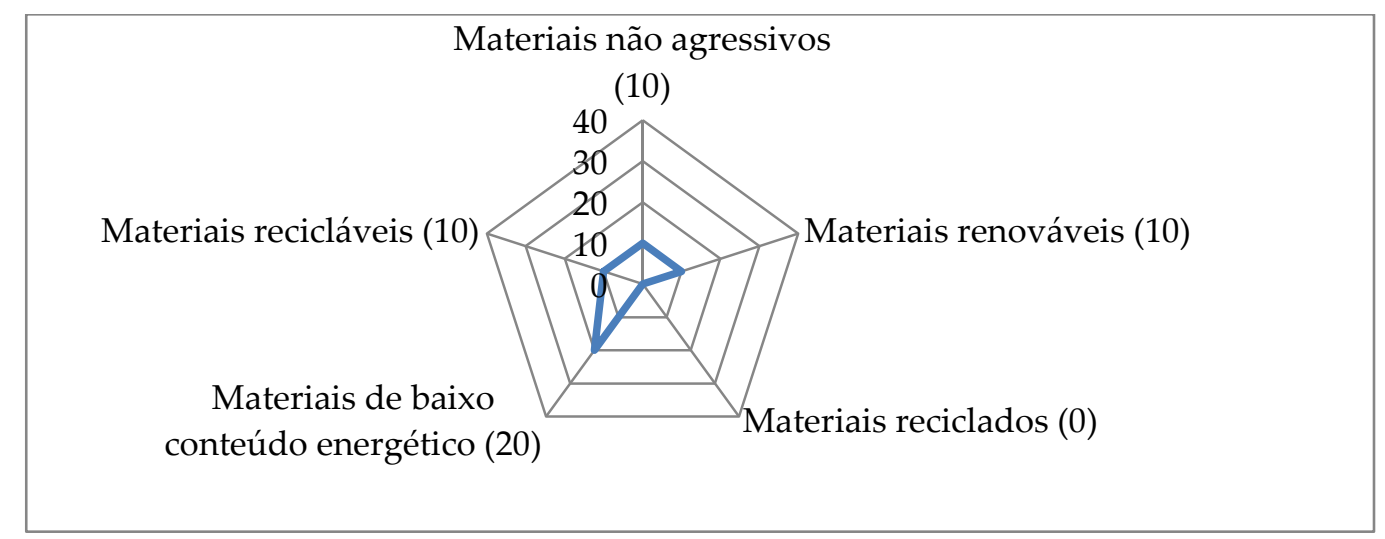

Figura 6. Estratégia 1: Seleção de materiais de baixo impacto

Fonte: Dados da pesquisa, (2012).

A baixa prioridade desta estratégia, (10), é justificada pelo fato da empresa não utilizar no produto materiais tóxicos, exceto a solda que é utilizada em pequena quantidade, apenas $0,16 \mathrm{~kg}$, ou com problemas já conhecidos, escassos ou em risco de extinção; utilizar materiais que demandam pouca energia em sua transformação (algodão orgânico) e priorizar a utilização de materiais que podem ser reciclados, tornando-os materiais para serem reutilizados na fabricação de novos produtos. Para melhorar o desempenho ambiental do produto poderia se fazer uso do aço carbono reciclado.

Tratando-se da estratégia 2, que aborda a Redução de uso de materiais (Fig. 7) , todas as dimensões: "redução de peso", "redução de volume" e "racionalização de transportes" têm muita relevância e sempre são aplicadas. Assim, todas as dimensões e a estratégia resultam em prioridade (10), o que caracteriza baixa prioridade.

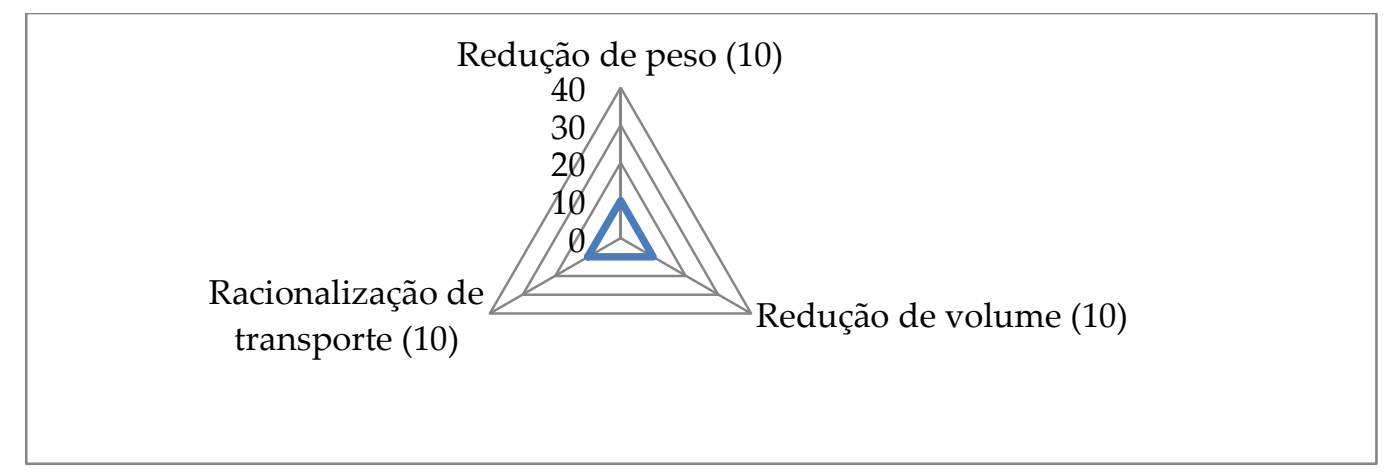

Figura 7. Estratégia 2: Redução de uso de materiais Fonte: Dados da pesquisa, (2012).

A baixa prioridade desta estratégia se dá em face dos materiais utilizados apresentarem menor peso (estrutura 1,84 kg, solda 0,16 kg e trama 1,5 Kg), o produto ter 
apenas um volume e pela minimização das despesas de transporte em que a empresa dar preferência à matéria-prima (trama de algodão orgânico) produzida no município de Santa Luzia - PB, uma vez que localmente não há disponibilidade deste material.

Quanto à estratégia 3, que se refere a otimização das técnicas de produção (Fig.8), a empresa percebe muita relevância e aplica sempre "técnicas de produção alternativa" e "redução do consumo e uso racional de energia".

A dimensão "redução de etapas do processo de produção" não é aplicável ao produto. Quanto às demais dimensões, não apresentam nenhuma relevância em face do aço carbono ser cortado e a trama ser confeccionada nas dimensões exatas, não acarretando a geração de resíduos.

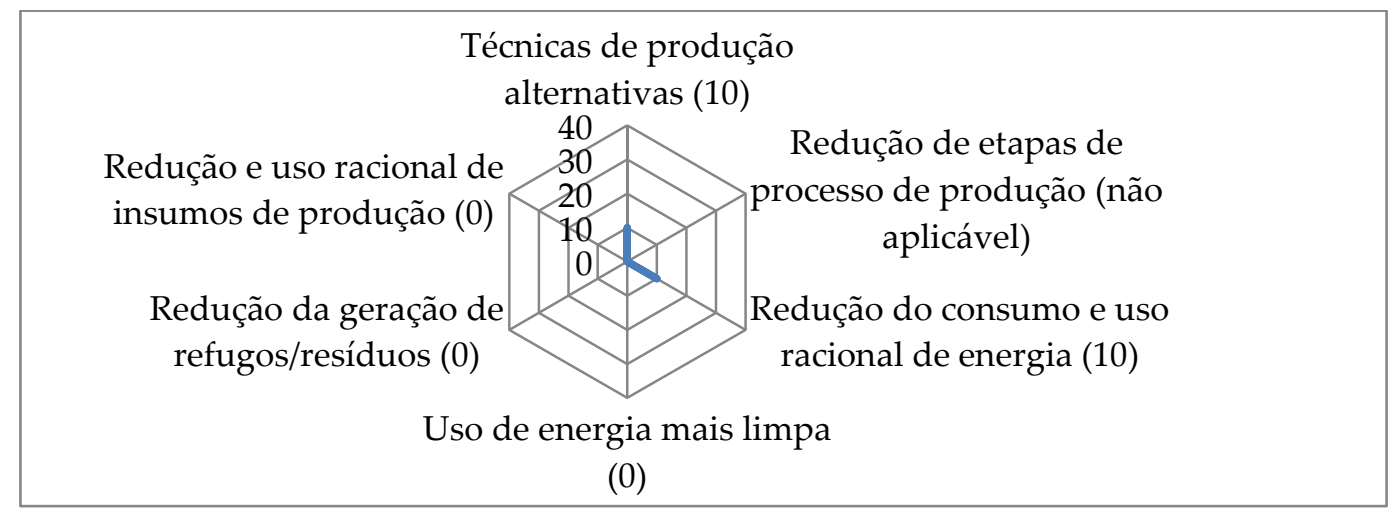

Figura 8. Estratégia 3: Otimização das técnicas de produção

Fonte: Dados da pesquisa, (2012).

Esta estratégia apresenta baixa prioridade $(3,3)$ porque a empresa utiliza técnicas de produção alternativa, a artesanal, para cobrir com a trama de algodão orgânico, também produzida artesanalmente, a estrutura do produto, o que leva a redução do consumo de energia. Também se utiliza de mecanismos para redução e uso racional de energia quando do processo de fabricação da estrutura do produto que necessita apenas de pequenos pontos de soldagem. Considerando-se que o consumo de energia elétrica é de apenas $0,11 \mathrm{kWh}$, a empresa entende que a utilização de fonte de energia renovável não é relevante.

Quanto à Estratégia 4, que aborda aspectos inerentes ao sistema de distribuição eficiente (Fig. 9), não é aplicável ao produto a dimensão "logística eficiente", pois a empresa fabrica o produto exclusivamente sob encomenda, o que faz com que não necessite de um sistema de logística que considere sua armazenagem e forma de distribuição.

Quanto às demais dimensões, apresentam baixa prioridade por terem aplicabilidade e relevância. O banco Carambola é embalado, de forma que não sofra 
nenhum dano durante o transporte, em uma única caixa de papelão confeccionada a partir de material reciclado, que pode ser reutilizada ou reciclável. Devido às dimensões e características do produto, não é viável a utilização de embalagem retornável.

Considerando as quatro dimensões, esta estratégia tem baixa prioridade $\mathbf{( 5 , 9 )}$.

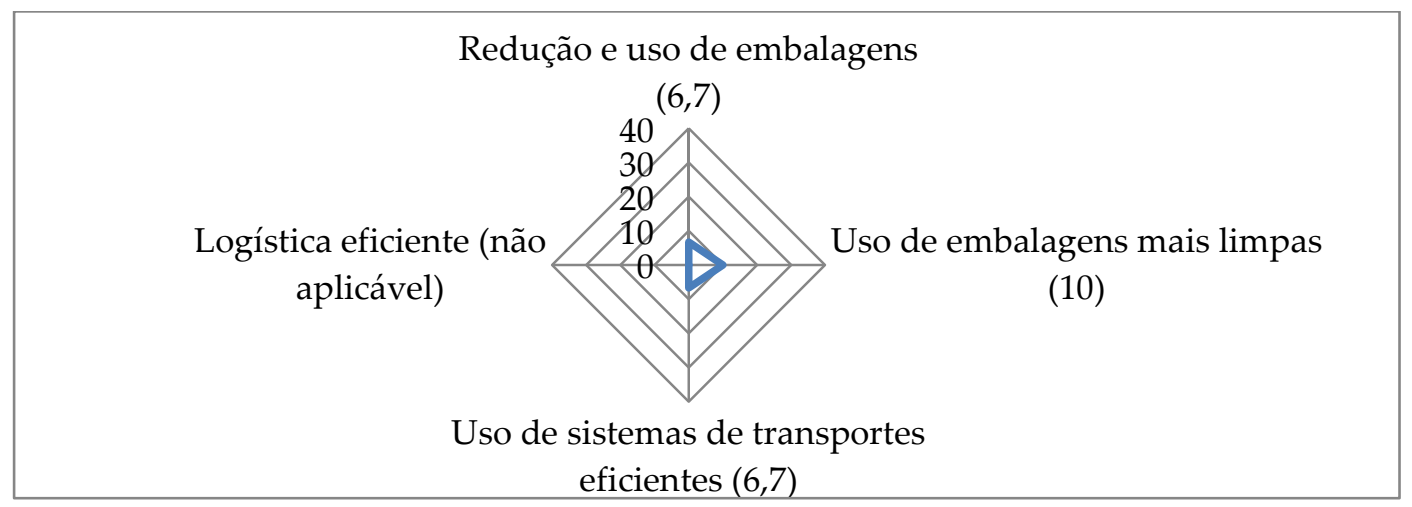

Figura 9. Estratégia 4: Sistema de distribuição eficiente

Fonte: Dados da pesquisa, (2012).

É inviável para a empresa utilizar outro meio de transporte, seja terrestre, aquaviário ou ferroviário, dada à localização do mercado consumidor concentrado nas regiões Sul e Sudeste e Distrito Federal e do volume de vendas, o que torna o transporte aéreo o meio adotado por apresentar custo mais baixo, rapidez e segurança.

No que tange a Estratégia 5, que trata da redução do impacto ambiental no nível de usuário (Fig. 10), para o banco Carambola, a "prevenção de desperdícios pelo design" tem muita relevância e sempre é aplicada, o que resulta em prioridade (10).

No que se referem às demais dimensões, não são aplicáveis. Isto ocorre porque o produto, quando do seu uso, não consome energia e, nem tampouco, necessita de outros materiais. Desta forma, esta estratégia apresenta baixa prioridade $(2,5)$.

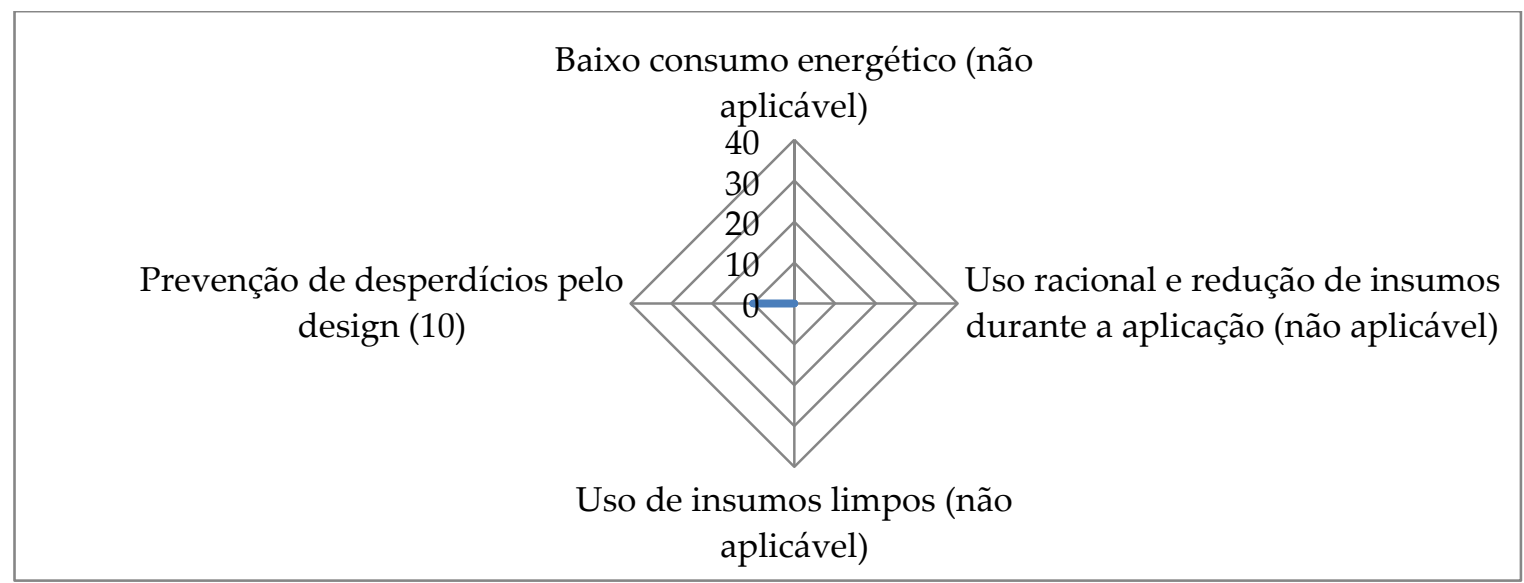

REUNIR - Revista de Administração, Contabilidade e Sustentabilidade

ISSN: 2237-3667 - Vol.5, nํ1, pp. 79-105, 2015. 
Figura 10. Estratégia 5: Redução do impacto ambiental no nível de usuário

Fonte: Dados da pesquisa, (2012)

A baixa prioridade desta estratégia se justifica porque o produto não consome energia durante o seu uso, bem como não utiliza materiais tóxicos ou perigosos durante a manutenção e limpeza que é feita apenas com espanador, pincel ou pano. O desgaste do produto pode ser sanado por reposição de componentes (trama ou estrutura) e pode ser melhorado e/ou adaptado ao estado da tecnologia ou as tendências da moda, conforme anseios e desejos dos clientes.

Em relação à estratégia 6 que se refere a otimização do tempo de vida do produto (Fig. 11), a dimensão "zelo do usuário com o produto" apresenta duas afirmativas: a primeira, "o produto apresenta características "especiais" em relação aos concorrentes", por ter muita relevância e sempre ser aplicada totaliza prioridade (10); a segunda, "o produto apresenta um conjunto de informações relacionadas à sua utilização e conservação", por não apresentar nenhuma relevância e nunca ser aplicada, culmina em prioridade zero (0). Neste caso a prioridade da dimensão é (5).

As demais dimensões apresentam muita relevância e sempre são aplicadas, de forma que a prioridade de cada é (10). Assim, constata-se que esta estratégia é de baixa prioridade (9).

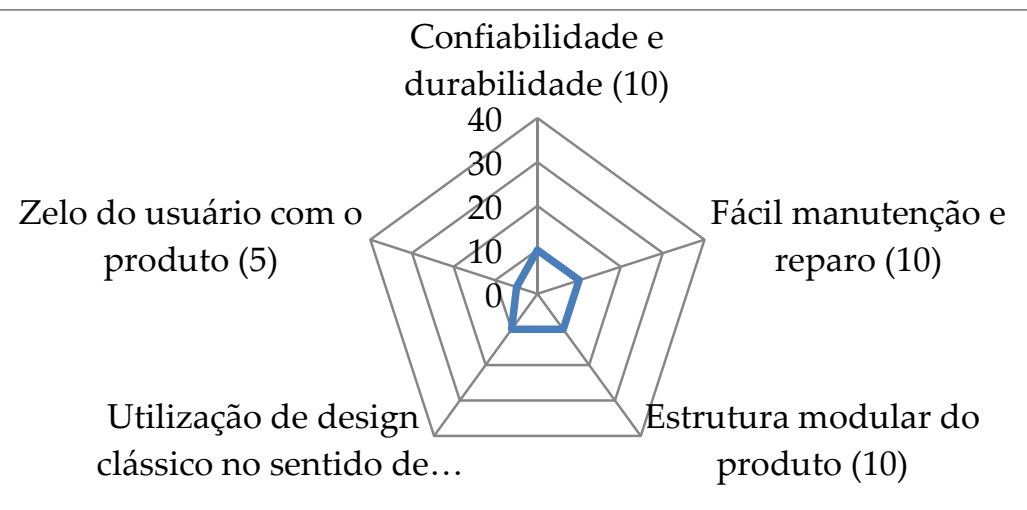

Figura 11: Estratégia 6: Otimização do tempo de vida do produto

Fonte: Dados da pesquisa (2012)

O banco Carambola é projetado para durar por tempo indeterminado, uma vez que os materiais utilizados conservam características como forma e cor e pode lidar com os encargos do uso intensivo, permitindo manutenção e reparos a partir de atividades de simples execução, pois os componentes são facilmente acessíveis e facilmente substituíveis, o que evita a eliminação do produto devido falhas em partes. 
O produto apresenta características especiais em relação aos concorrentes tendo em vista sua estrutura, materiais e estilo, o que lhe assegura apreciação pelo usuário. Dada suas características, ressalta-se que o produto não necessita de informações relacionadas à sua utilização e conservação.

Finalizando com a estratégia 7 que aborda a otimização do pós-uso (Fig. 12), evidencia-se que todas as dimensões apresentam baixa prioridade, sobretudo a "reciclagem de materiais", pois devido às características dos materiais utilizados nos componentes do produto, a empresa entende que esta dimensão é irrelevante, consequentemente não há aplicabilidade.

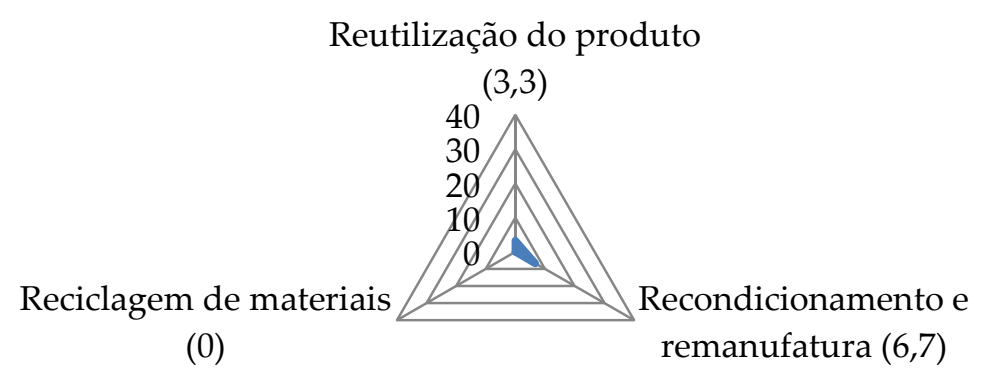

Figura 12: Estratégia 7: Otimização do pós-uso

Fonte: Dados da pesquisa, (2012).

Considerando todas as dimensões, a estratégia em análise se caracteriza como de baixa prioridade $(3,3)$. De acordo com os dados coletados, verifica-se que não é viável, nem tampouco necessária à adoção de um sistema de logística reversa objetivando a reutilização do produto, da mesma forma, são desnecessárias informações no produto sobre o propósito de sua reutilização ou mesmo instruções sobre sua desmontagem. Cabe ressaltar que devido os materiais e componentes utilizados, o produto pode ser reutilizado para o mesmo ou outro fim, caso seja reformado. Todavia não é possível a reciclagem dos materiais utilizados nos componentes do produto, haja vista, a impossibilidade de separação dos materiais que compõem o aço carbono, e, quanto ao algodão orgânico, este é biodegradável.

\subsection{Relação entre Intensividade dos Aspectos Ambientais (Ecodesign Pilot) e as Estratégias de Ecodesign (TEE)}

Quanto à relação entre a intensividade dos aspectos ambientais (Ecodesign PILOT) e as estratégias de ecodesign (TEE), verifica-se (Fig. 13) que o banco Carambola se 
apresenta intensivo em matéria-prima, ou seja, a maior parte dos impactos ambientais do produto é causada na primeira fase do ciclo de vida. Isto ocorre porque os processos de extração e de produção de matérias-primas (aço carbono e solda) causam a maior parte dos impactos ambientais. Todavia, destaca-se que as estratégias (TEE) associadas à esta característica (Ecodesign PILOT) apresentam baixa prioridade.

Ressalta-se que as demais características do Ecodesign PILOT convergem para as respectivas Estratégias da TEE, as quais se apresentam como baixa prioridade.

\section{Características do Ecodesign PILOT}

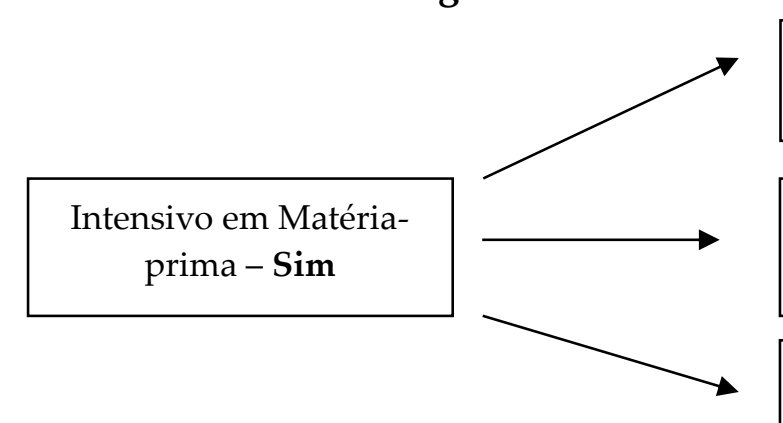

\section{Estratégias principais da TEE}

Desenvolvimento de novo conceito - Baixa prioridade

Seleção de materiais de baixo impacto Baixa prioridade Redução do uso de material - Baixa
prioridade

Otimização das técnicas de produção - Baixa prioridade

Sistema de distribuição eficiente - Baixa prioridade

Redução de imp. ambiental no nível do usuário - Baixa prioridade

Otimização do tempo de vida do produto -

Baixa prioridade

Otimização do pós-uso - Baixa prioridade

Intensivo em

Disposição - Não

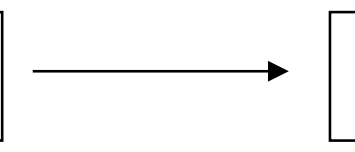

Figura 13 - Relação de complementaridade entre o Ecodesign PILOT e a TEE.

Com efeito, o fato dos resultados das ferramentas utilizadas apresentarem resultados, na sua maioria, convergentes, reforça-se a importância e necessidade do uso 
combinado do Ecodesign PILOT e da TEE para análise mais ampla do desempenho ambiental do produto.

Genericamente, as ferramentas de ecodesign têm muitos pontos em comum. O ponto crucial é fundir estratégias e ferramentas para estabelecer metas para o desenvolvimento de produtos onde a sustentabilidade é uma parte significativa (LUTTROPPE \& LAGERSTEDT, 2006). Todavia, é de grande valia para a empresa adotar o uso conjunto de ferramentas, uma vez que uma pode ser complementada por outra, viabilizando o alcance das metas estabelecidas.

\section{CONSIDERAÇÕES FINAIS}

O objetivo do presente trabalho foi avaliar até que ponto um produto concebido como verde de fato é verde. O produto escolhido foi o banco Carambola concebido e premiado internacionalmente como tal. Os aspectos ambientais do produto foram analisados a partir do uso de duas ferramentas de ecodesign: o Ecodesign PILOT e a TEE, as quais contemplam todas as etapas do ciclo de vida do produto, cujos resultados mostraram que de fato o produto pode ser considerado como verde.

Após a realização de todas as análises, pode-se elencar, entre outros, os seguintes aspectos ambientais do produto: os materiais utilizados não causam impactos ambientais substanciais; durante o processo produtivo e uso não há geração de resíduos; o consumo de energia na produção é mínimo; tem uma vida útil longa, e, se necessário pode repor partes sem descartá-lo; durante o uso não necessita de materiais ou métodos difíceis ou sofisticados específicos para manutenção e limpeza; pode ser reutilizado para o mesmo ou outros fins; a embalagem é feita com material reciclado e reciclável.

Em suma, em face do exposto, pode-se concluir que o banco Carambola, concebido como produto verde, à luz do Ecodesign PILOT e da TEE, é de fato um produto verde.

Contudo, para um melhor desempenho ambiental do produto, com base na ferramenta Ecodesign PILOT, sugere-se que a estrutura do banco seja confeccionada com materiais alternativos, ou seja, que seja substituido o aço carbono por madeira certificada e a solda por parafusos para minimização das emissões atmosféricas e redução do uso de materiais de fontes não renováveis.

Com efeito, cabe destacar a importância da ampliação das discussões em torno de produtos verdes, considerando por um lado a tendência de crescimento da produção e consumo desse tipo de produto e a possibilidade de uma efetiva contribuição para o desenvolvimento sustentável, e, por outro, a necessidade de um maior esclarecimento para as empresas e consumidores sobre o que de fato deve ser considerado produto verde, evitando a adoção de apelos ambientais com propósitos ludibriantes. 
Assim, espera-se a contribuição teórica e prática deste trabalho e sugere-se novas pesquisas objetivando a avaliação de outros produtos concebidos como verdes, ou produtos que, embora não tenham sido concebidos como tal, possam melhorar seu desempenho ambiental, fazendo-se uso de tais ferramentas que são de fácil utilização e funcionam como um guia para o designer melhorar o perfil ambiental do produto.

\section{REFERÊNCIAS}

ALBINO, V.; BALICE, A.; DANGELICO, R. M. Environmental strategies and green product development: na overview on sustainability-driven companies. Business Strategy and the Environment. v. 18, p. 83-96, 2009.

BAUMANN, H.; BOONS, F.; BRAGD, A. Mapping the green product development field: engineering, policy and business perspectives. Journal of Cleaner Production, v. 10, p. 409-425, 2002.

BREZET, H.; van HEMEL, C. Ecodesign, A promising approach to sustainable production and consumption. Edited by UNEP. Paris, 1997.

CONSELHO EMPRESARIAL BRASILEIRO PARA O DESENVOLVIMENTO

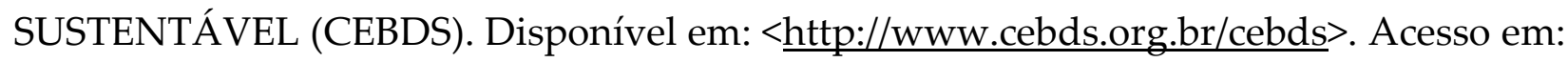
10 jan 2012.

DANGELICO, R. M.; PONTRANDOLFO, P. From green product definitions and classifications to the Green Option Matrix. Journal of Cleaner Production, v. 18, p. 1608$1628,2010$.

DIEHL. J. C.; CRUL, M.; BIJMA, A. Ecodesign in Central America, Ecodesign methodology: Product Improvement Tool (PIT). The Journal of Sustainable Product Design, v. 1, p. 197-205, 2001.

ECODESIGN Pilot: Product Investigation, Learning and Optimization Tool for Sustainable Product Development. Disponível em: $<$ http://www.ecodesign.at/pilot $>$ e $<$ http://www.ecodesign.at/assist $>$. Acesso em: 15 mai 2012.

FARGNOLI, M.; KIMURA, F. Sustainable Design of Modern Industrial Products. 13th CIRP International Conference on Life Cycle Engineering, 2006. 
FARGNOLI, M.; SAKAO, T. Coordinating ecodesign methods in early stages of industrial product design. International Journal of Environmentally Conscious Design \& Manufacturing. v. 14, n 2, p. 35-65, 2008.

GIL, A. C. Como elaborar projetos de pesquisa. 4. ed. - São Paulo: Ed. Atlas, 2002, 175 pp.

HAIR JR., J. F. et al. Fundamentos de métodos de pesquisa em administração. Tradução Lene Belon Ribeiro - Porto Alegre: Bookman, 2005, 471 pp.

HEPPERLE C. et al. Calculating lifecycle interdependencies based on eco-design strategies, IEEE. International Conference on Industrial Engineering and Engineering Management. p. 743-747, 2010.

HOCHSCHORNER, E.; FINNVEDEN, G. Evaluation of Two Simplified Life Cycle Assessment Methods. Int J LCA, v. 8 (3), p. 119-128, 2003.

HUR, T. et al. Simplified LCA and matrix methods in identifying the environmental aspects of a product system. Journal of Environmental Management, v.75, p. 229-237, 2005.

JÖNBRINK, A.; MELIN, H. E (2008). How central authorities can support ecodesign: Company perspectives . Nordic Council of Ministers Copenhagen: TemaNord 2008:569. 2008, 84 pp.

LUTTROPP, C.; LAGERSTEDT, J. EcoDesign and The Ten Golden Rules: generic advice for merging environmental aspects into product development. Journal of Cleaner Production, v. 14, p. 1396-1408, 2006.

MARIA, H.; RAINER, P.; WOLFGANG, W. ECODESIGN Toolbox for the Development of Green Product Concepts - Applied examples from industry. ECO-X Sustainable Recycling Management \& Recycling Network Centrope. International Conference and Workshop. Áustria, 2007.

MASANET, E.; HORVATH, A. Assessing the benefits of design for recycling for plastics in electronics: A case study of computer enclosures. Materials \& Design, v.28, issue 6, p. 1801-1811, 2007. 
MEDEIROS, M. C. et al. A pesquisa em ecodesign nos Congressos do P\&D Design. CONGRESSO BRASILEIRO DE PESQUISA E DESENVOLVIMENTO EM DESIGN, 9, 2010, São Paulo. Anais eletrônicos... São Paulo: Associação de Ensino e Pesquisa de Nível Superior de Design do Brasil (AEND/Brasil), 2010. Disponível em: Disponível em: $<$ http://blogs.anhembi.br/congressodesign/anais/>.Acesso em: 30 jul 2011.

MUÑOZ, I. et al. LCA and ecodesign in the toy industry: case study of a teddy bear incorporating electric and electronic components. Int J Life Cycle Assess, v. 14, p. 64-72, 2009.

NASCIMENTO, L. F.; VENZKE, C. S. Ecodesign. In VILELA JR, A.; DEMAJOROVIC, J (orgs.). Modelos e ferramentas de gestão ambiental: desafios e perspectivas para as organizações. São Paulo: Ed. Senac, 2006, p. 285-311.

OTTMAN, J., Stafford, E, Hartman, C. Avoiding Green Marketing Myopia. In Environment, 48(5), 22-36. 2006.

SANTOS, A. Estado da pesquisa em design sustentável no Brasil. SIMPÓSIO DE DESIGN SUSTENTÁVEL, 1ํ, 2009, Curitiba. Anais eletrônicos...Curitiba: Núcleo de Design e Sustentabilidade da Universidade Federal do Paraná, 2009. Disponível em: <www.design.ufpr.br/spds/anais.pdf $>$. Acesso em: 07 jul 2011.

SCHIAVONE, F.; PIERINI, M.; ECKERT, V. Strategy-based approach to eco-design: an innovative methodology for systematic integration of ecologic/economic considerations into product development process. J. Sustainable Design, v. 1, n. 1, p. 29-44, 2008.

TOMÉ, M. V. D.; BLUMENSCHEIN, R. N. Compra Responsável na Indústria da Construção. ENCONTRO ASSOCIAÇÃO NACIONAL DE PÓS-GRADUAÇÃO E PESQUISA EM AMBIENTE E SOCIEDADE, V, 2010, Florianópolis. Anais eletrônicos... Florianópolis: ANPPAS - Associação Nacional de Pós-Graduação e Pesquisa em Ambiente e Sociedade (ANPPAS), 2010. Disponível em: $<$ http://www.anppas.org.br/encontro5/index.php?p=gt>. Acesso em: 25 jul 2011.

UNITED NATIONS ENVIRONMENT PROGRAMME (UNEP). Disponível em: $<$ http://www.unep.org $>$. Acesso em: 13 jan 2011.

VENZKE, C. S. A situação do ecodesign em empresas moveleiras da região de Bento Gonçalves, RS: Análise da postura e das práticas ambientais. 2002. 126 f. Dissertação 
(Mestrado em Administração). Escola de Administração, da Universidade Federal do Rio Grande do Sul. Porto Alegre, RS.

VERGARA, S. C. Projetos e relatórios de pesquisa em administração. 3. ed. - São Paulo: Ed. Atlas, 2000, 92 pp.

VAN HEMEL, C.; CRAMER, J. Barriers and stimuli for ecodesign in SMEs. Journal of Cleaner Production, v. 10, p. 439-453, 2002.

WONG, Y. L.; LEE, K. M; YUNG, K. C. Model scenario for integrated environmental product assessment at the use of raw materials stage of a product. Resources, Conservation and Recycling, v. 54, p. 841-850, 2010.

XING, K.; ABHARY, K.; LUONG, L. IREDA: An integrated methodology for product recyclability and end-of-life design. The Journal of Sustainable Product Design, v. 3, p. 149-172, 2006. 